\title{
PSYCHE
}

\begin{tabular}{lll}
\hline Vol. 100 & 1993 & No. 3-4 \\
\hline
\end{tabular}

\section{BROODING BEHAVIOR IN THE BUG ELASMUCHA SIGNORETI (HETEROPTERA: ACANTHOSOMATIDAE)}

BY SHIN-ICHI KUDÔ ${ }^{1}$ AND TAICHI NAKAHIRA ${ }^{2}$

\section{INTRODUCTION}

Subsociality has been reported in many taxonomic groups within the Heteroptera, especially in the Pentatomomorpha (Melber and Schmidt 1977, Tachikawa 1991). In the family Acanthosomatidae, maternal care has been recorded for more than 10 species of three genera, Anaxandra, Sastragala and Elasmucha (Tachikawa 1991). However, the adaptive significance of this behavior has been confirmed by field experiments in only a few species (Melber and Schmidt 1975b, Honbo and Nakamura 1985, Kudô et al. 1989). There have been some observations of maternal attendance of offspring in Elamucha signoreti Scott (Tachikawa 1991). Nevertheless, a detailed report of its reproductive history remains unavailable. In the present paper, we describe oviposition and patterns of maternal behavior, as well as show the effects of the maternal behavior on survival of the offspring under field conditions.

\section{MATERIALS AND MethodS}

Observations and experiments were conducted in a forest in Toyotaki, Sapporo, Hokkaido, northern Japan, from August to September in 1991 and during August in 1992. At the study site, host

\footnotetext{
${ }^{1}$ Laboratory of Applied Zoology, Faculty of Agriculture, Hokkaido University, Sapporo, 060 Japan

${ }^{2}$ Systematic Entomology, Faculty of Agriculture, Hokkaido University, Sapporo, 060 Japan

Manuscript received 29 March 1993.
} 
plants of E. signoreti, the vine Hydrangea petiolaris Sieb., grow on pine tree supports. The E. signoreti population was rather small: less than 30 females with offspring were discovered on the host plant during the two-year research period. We marked individual females attending the offspring with quick-drying paint, tagged oviposition sites, and then monitored the females and offspring. To count the eggs, females were temporarily removed from the clutches; however, this did not disturb the subsequent behavior of the females.

In many subsocial insects, brooding females show specific defensive behavior when disturbed (e.g., Eberhard 1975). To observe behavior against disturbance in the field, females with offspring, females that had left the offspring and males were stimulated by shaking a small black ball ( $4 \mathrm{~mm}$ in diameter) in front of them at a distance of about $5 \mathrm{~mm}$. Five females with eggs were brought into the laboratory and placed with a potential predator, an asopine bug nymph, for detailed observations.

To examine ovarian development during the period of maternal care, we dissected females with eggs $(n=11)$, females with late 1 stinstar nymphs $(n=5)$ and those that had just left 2 nd instar nymphs $(n=3)$.

In 1992, to evaluate the adaptive significance of female attendance, 7 females were removed from their egg masses in the field. Another 5 females with eggs were kept intact as controls. Six days after the removal, the number of surviving eggs or nymphs were counted in each of the clutches and the survival rate was compared between the two groups.

\section{Results AND Discussion}

Oviposition usually occurred in early August. Eggs were laid in a compact mass usually on the undersurface of host leaves, but one egg mass was found on the sepal. The number of eggs per clutch was, on average, $33.79(\mathrm{SD}=4.35$; range, $21-36 ; \mathrm{n}=19)$. Females always straddled their offspring (Fig. 1). Of 11 females monitored in 1991, one disappeared from her egg mass, and another was confirmed to have been killed by a web building spider. These two egg masses which were left without a female were completely destroyed before hatching, while the other nine clutches with a female successfully hatched. First instar nymphs always form a 


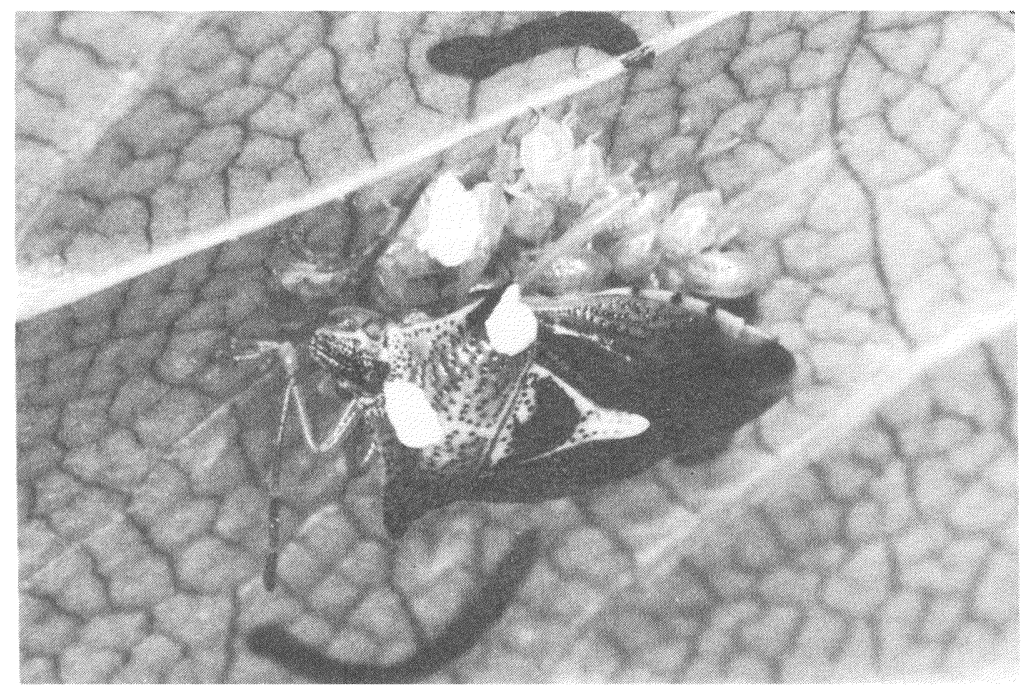

Fig. 1. An Elasmucha signoreti female with 1st-instar nymphs on a leaf of the host plant, Hydrangea petiolaris.

tight aggregation and probably do not feed. After molting to the 2nd instar, nymphs moved from the oviposition site to the inflorescence in aggregations, to feed on fruit. We observed three marked females straddling newly-molted 2nd-instar nymphs which remained at the oviposition site. However, no females attended 2nd- or later-instar nymphs that had left the oviposition site. In other Elasmucha spp., parent females often attend the 2nd- or laterinstar nymphal aggregation away from the oviposition site (Frost and Haber 1944, Melber and Schmidt 1975a, Honbo and Nakamura 1985, Kudô et al. 1989). Thus, E. signoreti females probably desert their offspring at the earliest developmental stage among the related species. Five marked females were observed alone on the host at least once after deserting the offspring from the middle to the end of August in 1991. Although males were found on the host before the females disappeared, no copulation was observed. Moreover, none of the females produced additional clutches.

Females with offspring probably took no food: their ovaries had no chorionated eggs and contained only undeveloped oocytes (the largest oocyte was always less than $0.1 \mathrm{~mm}$ long) during the period of maternal care. 
When disturbed, brooding females showed almost the same aggressive behavior as in other Elasmucha spp. (Melber and Schmidt 1975a, Melber et al. 1980, Kudô et al. 1989, Kudô 1990): jerking the body rapidly, tilting the body toward the source of the disturbance, and wing fanning. In the laboratory, E. signoreti females with eggs dealt with an asopine bug approaching them by employing various combinations of the responses described above. Against a disturbance made by a small black ball in the field, all of the females with eggs $(n=10)$, those with 1 st-instar nymphs $(n=8)$ and those with 2 nd-instar nymphs remaining at the oviposition site $(n=3)$ responded with some of the above behaviors. However, solitary females that left offspring $(n=4)$ and males $(n=12)$ retreated from the disturbance or dropped from plants without displaying any aggressive behavior.

Maternal brooding in E. signoreti was highly effective in protecting offspring from predation. Five out of the seven clutches from which females were removed were attacked and disappeared from the leaves within six days, while most of the offspring survived in the five control clutches. The offspring survival in the experimental group (Mean $=0.270, \mathrm{SD}=0.461$ ) was significantly lower than that in the control group (Mean $=0.978, \mathrm{SD}=0.036)$ (Mann-Whitney $U$ test, $\mathrm{p}=0.0065$ ). Several spiders and predatory bug nymphs (Asopinae and Nabidae) were observed to feed on eggs and nymphs. Ants, which were often observed on host plants, probably preyed on $E$. signoreti eggs because no chorion remained on leaves from which eggs disappeared. Egg parasitoids have often been recorded as an important mortality agent of subsocial bugs (ex., Eberhard 1975, Ralston 1977, Nakamura 1990). However, as in other studies determining egg mortality agents of Elasmucha (Melber and Schmidt 1975b, Melber et al. 1980, Honbo and Nakamura 1985, Kudô et al. 1989), no egg parasitism was observed in $E$. signoreti even when parent females were removed from eggs.

The maternal behavior in E. signoreti apparently functions as physical defense of offspring against arthropod predators. THis is also the case in other Elasmucha spp. (Melber and Schmidt 1975b, Melber et al. 1980, Honbo and Nakamura 1985, Kudô et al. 1989) and other subsocial bugs (e.g., Tallamy and Denno 1981). Predation pressure is probably the primary selective factor leading to the maternal care commonly observed in Elasmucha bugs. 


\section{SUMMARY}

Reproductive behavior in the subsocial bug Elasmucha signoreti is described. Females usually deposited eggs in a compact mass on a leaf of the host plant, Hydrangea petiolaris, and straddled the offspring until the 2 nd instar when they left the oviposition site. While attending offspring, a female's ovaries were invariably undeveloped. When disturbed, attending females showed aggressive responses. Effectiveness of maternal behavior against arthropod predation was demonstrated by a female removal experiment in the field.

\section{ACKNOWLEDGMENTS}

We thank L. Tsukamoto for her comments on the manuscript, and Prof. S. Takagi, Hokkaido Univ., for his encouragement. This study was supported in part by a Grant-in-Aid from the Ministry of Education, Science and Culture, Japan.

\section{LiteratuRe Cited}

EBERHARD, W. G.

1975. The ecology and behavior of a subsocial pentatomid bug and two scelionid wasps: Strategy and counter strategy in a host and its parasites. Smithson, Contrib. Zool. 205: 1-39.

Frost, S. W. AND HABER, V. R.

1944. A case of parental care in the Heteroptera. Ann. Entomol. Soc. Am. 37: 161-166.

Honbo, Y. AND NAKAMURA, K.

1985. Effectiveness of parental care in the bug Elasmucha putoni Scott (Hemiptera: Acanthosomidae). Jpn. J. Appl. Ent. Zool. 29: 223-229. (In Japanese with English summary)

KuDô, S.

1990. Brooding behavior in Elasmucha putoni (Heteroptera: Acanthosomatidae), and a possible nymphal substance triggering guarding responses. Appl. Entomol. Zool. 25: 431-437.

Kudô, S., SATô, M. AND ÔHARA, M.

1989. Prolonged maternal care in Elasmucha dorsalis (Heteroptera: Acanthosomatidae). J. Ethol. 7: 75-81.

Melber, A. AND SChMidT, G. H.

1975a. Sozialverhalten zweier Elasmucha-Arten (Heteroptera: Insecta). Z. Tierpsychol. 39: 403-414.

1975b. Ökologische Bedeutung des Sozialverhaltens zweier Elasmucha-Arten (Heteroptera: Insecta). Oecologia 18: 121-128.

1977. Sozialphänomene bei Heteropteren. Zoologica 127: 19-53. 
Melber, A., Hölscher, L. AND Schmidt, G. H.

1980. Further studies on the social behaviour and its ecological significance in Elasmucha grisea L. (Hem.-Het.: Acanthosomatidae). Zool. Anz., Jena 205: 27-38.

NAKAMURA, $K$.

1990. Maternal care and survival in a Sumatran bug, Physomerus grossipes (Hemiptera, Coreidae). In : S. F. Sakagami, R. Ohgushi \& D. W. Roubik (eds), Natural History of Social Wasps and Bees in Equatorial Sumatra, pp. 233-243. Hokkaido University Press, Sapporo.

RALSTON, J. S.

1977. Egg guarding by male assassin bugs of the genus Zelus (Hemiptera: Reduviidae). Psyche 84: 103-107.

TACHIKAWA, S.

1991. Studies on Subsocialities of Heteroptera in Japan. Tokyo Agricultural University Press, Tokyo 167pp. (In Japanese)

Tallamy, D. W. and Denno, R. F.

1981. Maternal care in Gargaphia solani (Hemiptera; Tingidae). Anim. Behav. 29: 771-778. 

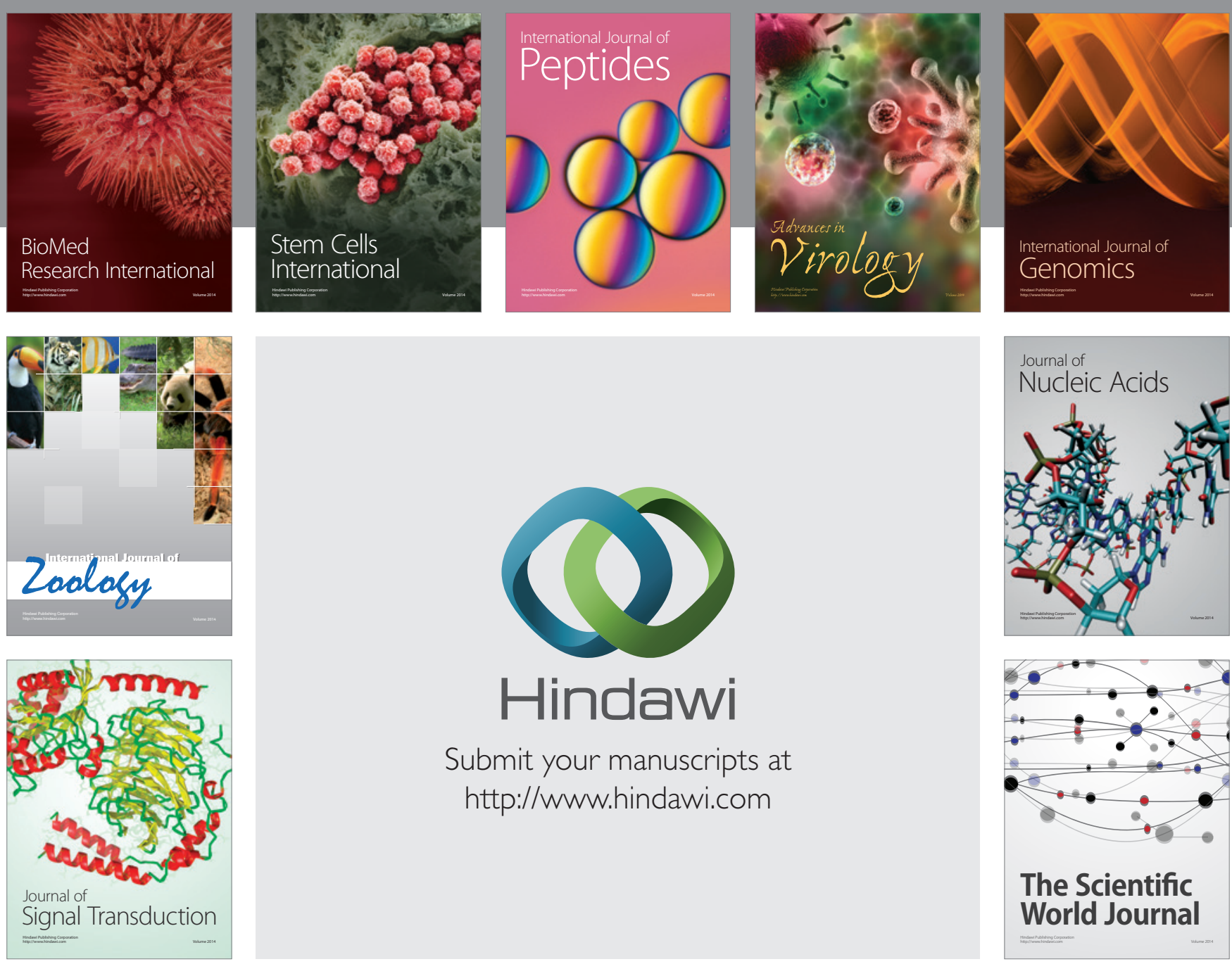

Submit your manuscripts at

http://www.hindawi.com
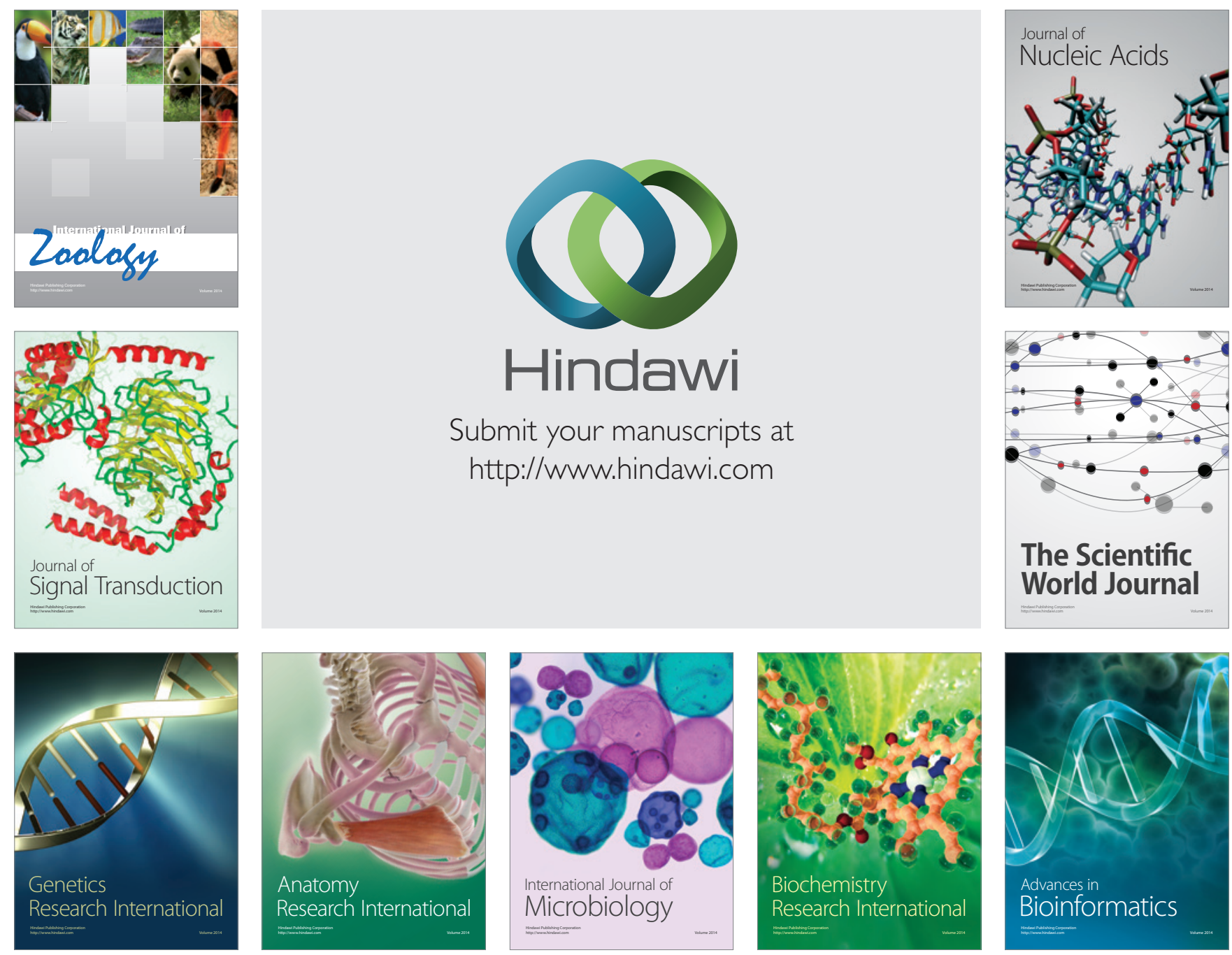

The Scientific World Journal
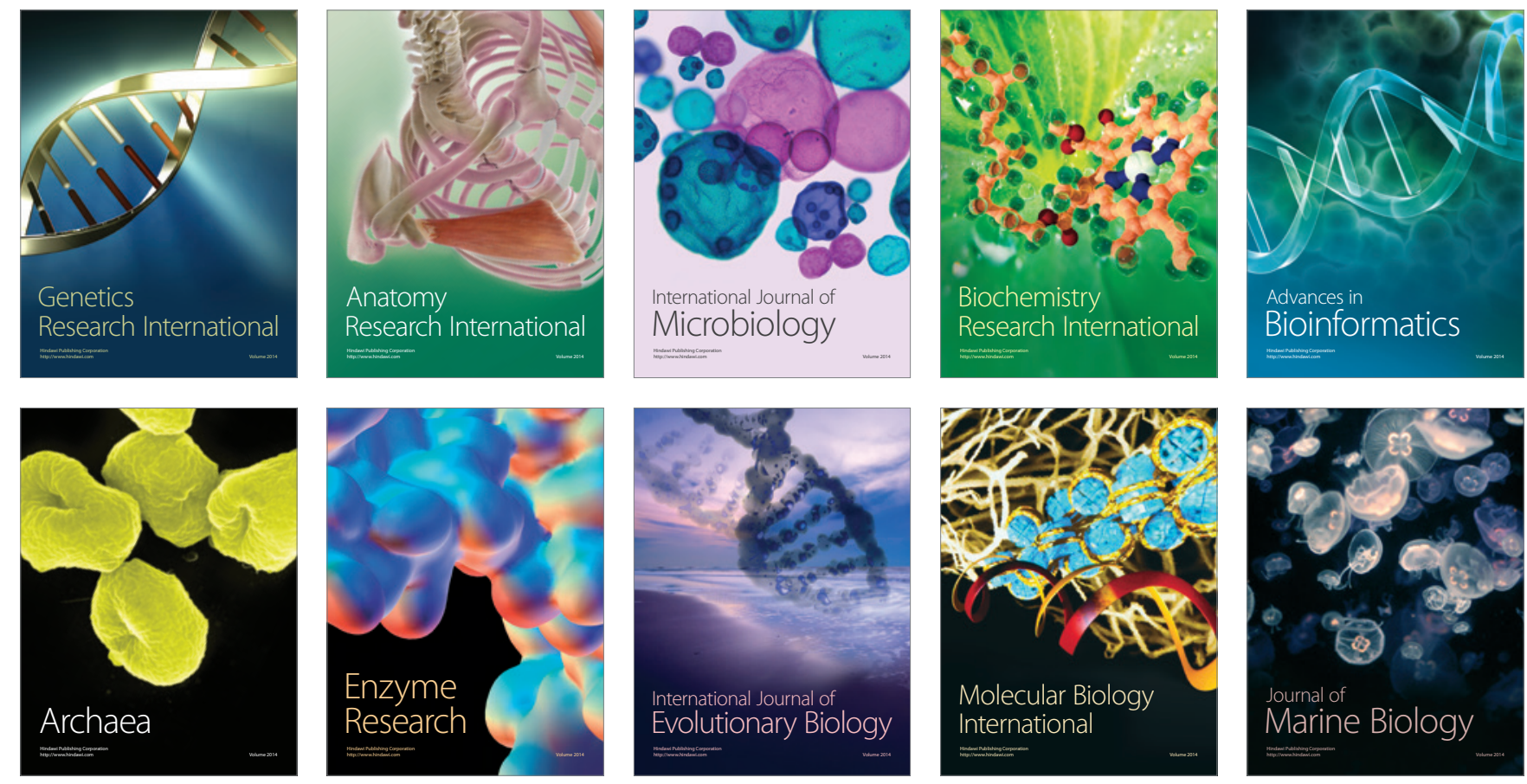